\title{
Etanercept in the treatment of Graves' ophthalmopathy with primary hypothyroidism and rheumatoid arthritis
}

\author{
OLIVERA BOSKOVIC ${ }^{l}$, SANJA MEDENICA ${ }^{1,2}$, NEMANJA RADOJEVIC ${ }^{2,3}$, MILOS ZARKOVIC ${ }^{4}$ \\ 'Department of Endocrinology, Internal Medicine Clinic, Clinical Center of Montenegro, Podgorica, Montenegro \\ ${ }^{2}$ Faculty of Medicine, University of Montenegro, Podgorica, Montenegro \\ ${ }^{3}$ Center for Pathology and Forensic Medicine, Clinical Center of Montenegro, Podgorica, Montenegro \\ ${ }^{4}$ Department of Thyroid Gland Disease, Clinic of Endocrinology, Diabetes and Metabolic Diseases, Clinical Center of Serbia, \\ School of Medicine, University of Belgrade, Belgrade, Serbia
}

\begin{abstract}
Graves' ophthalmopathy $(G O)$ is an autoimmune disease affecting ocular and orbital tissues. Overproduction of tumor necrosis factor $\alpha(T N F-\alpha)$ in rheumatoid arthritis $(R A)$ and GO has destructive consequences.

The subject of this paper is a case of a female patient initially diagnosed with primary hypothyroidism substitution with levothyroxine, and subsequent diagnosis of $R A$ with insufficient therapeutic efficacy of a standard medication. Three years later, the patient presented symptoms and signs of GO. Etanercept was administrated for RA, and after four months, an improvement of the eye symptoms and reduced exophthalmos were observed and confirmed using visual methods. Graves' ophthalmopathy association with primary hypothyroidism is uncommon. The treatment of RA using etanercept led to clinical improvement of GO symptoms, which indicates that $R A$ and GO may share similar pathogenic features.

The paper suggests that etanercept may suppress the symptoms and clinical signs of GO. However, controlled trials are needed to further evaluate the effect of TNF- $\alpha$ inhibitors, particularly etanercept, and to compare its side effects with the current options for medical treatment.
\end{abstract}

Key words: rheumatoid arthritis, TNF, etanercept, Graves' ophthalmopathy.

(Centr Eur J Immunol 2019; 44 (4): 463-465)

\section{Dear Editor,}

In a relevant literature, Graves' ophthalmopathy (GO) is defined as an autoimmune disease affecting ocular and orbital tissues [1], typically appearing in hyperthyroidism. Orbital fibroblasts have the central position in the pathogenesis of GO. Fibrocytes demonstrate an increased expression of the thyrotropin receptor (TSHR), comparable to the levels of thyroid epithelial cells, and ligation leads to a marked up-regulation of tumor necrosis factor (TNF)- $\alpha$ and interleukin (IL)-6 cytokine production [2]. Receptors for TNF- $\alpha$, proinflammatory cytokine, have been demonstrated in thyroid follicular cells, indicating that TNF- $\alpha$ has been implicated in the cytotoxic mechanisms leading to the thyroid gland destruction in autoimmune thyroid disease [3]. Etanercept is a TNF inhibitor and, in clinical practice, is used for treatment of rheumatoid arthritis (RA).
This paper presents a female patient with both GO and RA, who was treated with, inter alia, etanercept for RA. This treatment led to an improvement of eye symptoms and the exophthalmos was reduced.

A 37-year-old woman complained of sleepiness, apathy, and fatigue. Her hormonal analyses were as follows: thyrotropin (TSH) $11 \mathrm{mU} / \mathrm{l}$ (reference range 0.47-5.01 mU/l), free tetraiodothyronine (fT4) $10.5 \mathrm{pmol} / \mathrm{l}$ (reference range 12-22 pmol/l), anti-thyroid peroxidase antibodies (TPOAbs) $364.5 \mathrm{IU} / \mathrm{ml}$ (reference range $<12 \mathrm{IU} / \mathrm{ml}$ ), antithyroglobulin antibodies (TgAbs) $180.3 \mathrm{IU} / \mathrm{ml}$ (reference range $<12 \mathrm{IU} / \mathrm{ml}$ ), and anti-thyrotropin receptor antibodies (TRAbs) $4.54 \mathrm{IU} / \mathrm{ml}$ (reference range $<1 \mathrm{IU} / \mathrm{ml}$ ). Due to primary hypothyroidism, levothyroxine substitution was initiated. Ultrasonography of the thyroid gland showed its heterogeneous structure with a colloid nodule of the right

Correspondence: Sanja Medenica MD PhD, Department of Endocrinology, Internal Medicine Clinic, Clinical Center of Montenegro, Ljubljanska bb, 81000 Podgorica, Montenegro, e-mail: medenicasanja@gmail.com Submitted: 21.01.2018; Accepted: 28.02.2018 
Table 1. Values of Graves' ophthalmopathy related parameters

\begin{tabular}{|c|c|c|c|}
\hline Parameter & $\begin{array}{l}\text { Values at the } \\
\text { time of GO } \\
\text { appearance }\end{array}$ & $\begin{array}{l}\text { Values after } \\
\text { etanercept } \\
\text { treatment }\end{array}$ & $\begin{array}{l}\text { Reference } \\
\text { range }\end{array}$ \\
\hline $\mathrm{TSH}$ & 2.26 & 0.84 & $0.47-5.01 \mathrm{mU} / \mathrm{l}$ \\
\hline TPOAbs & 273.5 & 45.0 & $<12 \mathrm{IU} / \mathrm{ml}$ \\
\hline TgAbs & 11.2 & 32.5 & $<12 \mathrm{IU} / \mathrm{ml}$ \\
\hline TRAbs & 4.54 & 1.54 & $<1 \mathrm{IU} / \mathrm{ml}$ \\
\hline CAS & 4 & 1 & \\
\hline \multicolumn{4}{|l|}{ Visus } \\
\hline right eye & 1.0 & 1.0 & $0.1-1.0$ \\
\hline left eye & 1.0 & 1.0 & \\
\hline \multicolumn{4}{|l|}{$\mathrm{IOP}(\mathrm{mm} \mathrm{Hg})$} \\
\hline right eye & 18 & 20 & $12-22 \mathrm{~mm} \mathrm{Hg}$ \\
\hline left eye & 22 & 20 & \\
\hline \multicolumn{4}{|l|}{ Exophthalmos" } \\
\hline right eye & 23 & 21 & $\leq 18 \mathrm{~mm}$ \\
\hline left eye & 23 & 21 & \\
\hline \multicolumn{4}{|l|}{ CT } \\
\hline $\begin{array}{l}\text { right } \\
\text { superior } \\
\text { rectus } \\
\text { muscles }\end{array}$ & 8.3 & 8.0 & $<4 \mathrm{~mm}$ \\
\hline $\begin{array}{l}\text { left superior } \\
\text { rectus } \\
\text { muscles }\end{array}$ & 8.5 & 7.5 & \\
\hline \multicolumn{4}{|c|}{$\begin{array}{l}\text { GO - Graves' ophthalmopathy, TSH - thyrotropin, TPOAbs - anti-thyroid } \\
\text { peroxidase antibodies, TgAbs - anti-thyroglobulin antibodies, TRAbs - anti- } \\
\text { thyrotropin receptor antibodies, CAS - clinical activity score, IOP - intraocular } \\
\text { pressure, CT-computed tomography, }{ }^{2} \text { Hertel exophthalmometer by Oculus, } \\
\text { Germany }\end{array}$} \\
\hline
\end{tabular}

lobe (15 $\mathrm{mm}$ in diameter). The patient was a smoker for the last 30 years. Her parents were middle aged when they suddenly passed, and her sister suffered from psoriatic arthritis.

At about the same time, she presented with pain in the small joints of hands, knees, and jaw, numbness in the forearms and lower legs, and had difficulties climbing stairs. She was diagnosed with seropositive RA, with the following laboratory results: RF $122.7 \mathrm{IU} / \mathrm{ml}$ (reference range $<53 \mathrm{IU} / \mathrm{ml}$ ), Waaler-Rose and latex tests were positive, and anti-CCP was 813.6 (reference range $<18 \mathrm{IU} / \mathrm{ml}$ ). In the following years, the patient was treated with chloroquine, hydroxychloroquine, sulfasalazine, and methotrexate, in sequence.

After three years, she began complaining of orbital ache, diplopia (Gorman score - intermittent diplopia). Physical examination revealed watery eyes, bilateral eyelid edema, and eyelid erythema as well as conjunctival eyelid redness and exophthalmos. Ophthalmological examination results, hormonal values, and imaging method results are presented in Table 1. At the time, she was euthyroid. She was advised in accordance with the Consensus statement of the European Group on Graves' ophthalmopathy (EUGOGO) regarding the management of GO [4]. Over this time, the disease progressed to a moderate form. The administration of glucocorticoids was initiated and prednisone oral $0.5 \mathrm{mg} / \mathrm{kg}$ tapered down for 6 weeks. No significant improvement was achieved.

Eighteen months after GO diagnosis, due to the insufficient therapeutic efficacy of her previous RA treatment, etanercept was administered in combination with methotrexate. Etanercept was given in a dose of $25 \mathrm{mg}$ twice a week subcutaneously. After four months, an improvement of her eye symptoms and reduction in exophthalmos were noticed (Table 1). She experienced only mild eyelids edema.

The prevalence of GO in primary euthyroid and hypothyroid patients ranges between $1.6 \%$ and $8.6 \%$ [5]. Using etanercept in RA caused a clinical improvement of GO symptoms and signs. Visualization methods showed the reduction in the thickness of the extraocular muscles.

TRAbs in GO combine with the TSH receptors in retro-orbital tissues cause the lymphocytic infiltration and production of cytokines and glycosaminoglycans. TRAb is an antibody, which confirms the autoimmune form of GO. Fibrocytes in GO start to infiltrate orbital tissues during the inflammation process leading to overproduction of TNF- $\alpha$. TNF- $\alpha$ has been suggested as a possible mediator of increased expression in the major histocompatibility complex (MHC) class I molecules on thyroid epithelial cells in GO.

Some novel immunosuppressors have already been employed in clinical studies and have shown interesting results, although the lack of randomized and controlled trials suggests caution in their use in clinical practice [6]. Studies in the body of literature have attempted to determine whether etanercept is effective in reducing the clinical signs of GO and whether it can be administered safely for a prolonged period of time without side effects. The effect of the TNF inhibitor, etanercept, on GO was discussed in a pilot study in 2005 [7], and the study showed a marked improvement in the evolution of the disease.

The presented case suggests that etanercept may suppress the symptoms and clinical signs in GO, but controlled trials are needed to further evaluate the effect of TNF- $\alpha$ inhibitors, particularly etanercept, and to compare its side effects with the current options for medical treatment. It is important to note that new discoveries about immunopathogenesis of GO will increase the application of TNF- $\alpha$ inhibitors in GO treatments, which is especially important for the patients at risk of progressive and severe diseases. 


\section{Acknowledgements}

The case was presented as an oral presentation at the International Clinical Update in Endocrinology (ICUE), during the "Thyroid cases" session. It was held on February $1^{\text {st }}$ and $2^{\text {nd }}, 2014$ in Hyderabad, India.

Authors wish to thank Sreten Kavaric, MD PhD, and Koviljka Kazic, MD, for providing professional assistance.

The authors declare no conflict of interest.

\section{References}

1. Eichhorn K, Harrison AR, Bothun ED, et al. (2010): Ocular treatment for thyroid eye disease. Expert Rev Ophthalmol 5: 313-325.

2. Douglas RS, Gupta S (2011): The pathophysiology of thyroid eye disease (TED): implications for immunotherapy. Curr Opin Ophthalmol 22: 385-390.

3. Díez JJ, Hernanz A, Medina S, et al. (2002): Serum concentrations of tumour necrosis factor-alpha (TNF-alpha) and soluble TNF-alpha receptor $\mathrm{p} 55$ in patients with hypothyroidism and hyperthyroidism before and after normalization of thyroid function. Clin Endocrinol (Oxf) 57: 515-521.

4. Bartalena L, Baldeschi L, Dickinson A, et al. (2008): Consensus statement of the European Group on Graves' orbitopathy (EUGOGO) on management of GO. Eur J Endocrinol 158: 273-285.

5. Eckstein AK, Lösch C, Glowacka D, et al. (2009): Euthyroid and Primarily Hypothyroid Patients Develop Milder and Significantly More Asymmetrical Graves Ophthalmopathy. $\mathrm{Br}$ J Ophthalmol 93: 1052-1056.

6. Campi I, Vannucchi G, Salvi M (2016): Therapy of endocrine disease: Endocrine dilemma: management of Graves' orbitopathy. Eur J Endocrinol 175: R117-133.

7. Paridaens D, van den Bosch WA, van der Loos TL, et al. (2005): The effect of etanercept on Graves' ophthalmopathy: a pilot study. Eye (Lond) 19: 1286-1289. 